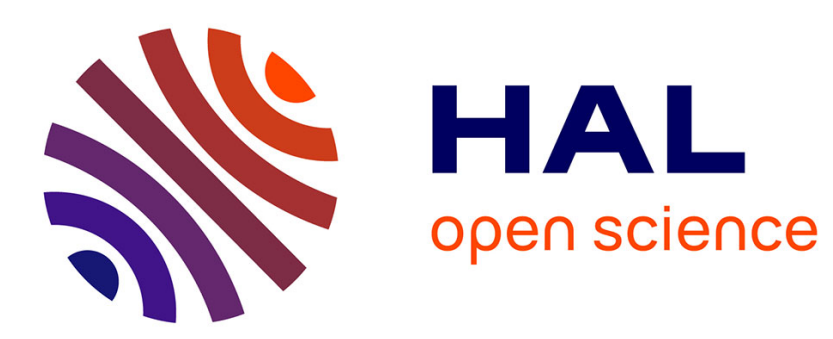

\title{
Satellite-based assessment and in situ validation of solar irradiation maps in the Republic of Djibouti
} Benjamin Pillot, Marc Muselli, Philippe Poggi, João Batista Dias

\section{To cite this version:}

Benjamin Pillot, Marc Muselli, Philippe Poggi, João Batista Dias. Satellite-based assessment and in situ validation of solar irradiation maps in the Republic of Djibouti. Solar Energy, 2015, 120, pp.603-619. 10.1016/j.solener.2015.08.015 . hal-01199143

\section{HAL Id: hal-01199143 \\ https://hal.science/hal-01199143}

Submitted on 15 Sep 2015

HAL is a multi-disciplinary open access archive for the deposit and dissemination of scientific research documents, whether they are published or not. The documents may come from teaching and research institutions in France or abroad, or from public or private research centers.
L'archive ouverte pluridisciplinaire HAL, est destinée au dépôt et à la diffusion de documents scientifiques de niveau recherche, publiés ou non, émanant des établissements d'enseignement et de recherche français ou étrangers, des laboratoires publics ou privés. 


\title{
Satellite-based assessment and in situ validation of solar irradiation maps in the Republic of Djibouti
}

\author{
Benjamin Pillot ${ }^{\mathrm{a}, *}$, Marc Muselli ${ }^{\mathrm{b}}$, Philippe Poggi ${ }^{\mathrm{b}}$, João Batista Dias ${ }^{\mathrm{a}}$ \\ ${ }^{a}$ Universidade do Vale do Rio dos Sinos, Programa de Pós-Graduação em Engenharia Mecânica, Avenida Unisinos 950, 93022-000 São Leopoldo, Brasil \\ ${ }^{b}$ Université de Corse, UMR CNRS 6134 SPE, Route des Sanguinaires, 20000 Ajaccio, France
}

\begin{abstract}
As well as for Sub-Saharan Africa, solar energy presents many relevant standalone applications for remote populations of the Republic of Djibouti. Therefore, in order to estimate the significance and the distribution of the solar resource throughout the country, we have retrieved the first hourly global irradiation maps of the country, at $0.05^{\circ}$ resolution and for the period 2008-2014, using the OSI SAF satellite-derived model. To assess the accuracy of this solar atlas, we have then compared estimates with ground measurements collected between 2010 and 2013 by temporary weather stations carried out on 4 different sites. The results of this comparison have shown a good precision of the global process, with for the daily irradiation a maximum relative error of $8.05 \%$ and a minimum correlation coefficient of 0.8892 . Finally, the solar irradiation maps extracted from the atlas show the solar potential is substantial with a daily mean irradiation equal to $5.92 \mathrm{kWh} / \mathrm{m}^{2}$, and also spatially and temporally consistent, with a daily standard deviation of $0.216 \mathrm{kWh} / \mathrm{m}^{2}$ and a yearly range between $5.08 \mathrm{kWh} / \mathrm{m}^{2}$ day and $6.69 \mathrm{kWh} / \mathrm{m}^{2}$ day.
\end{abstract}

Keywords: satellite estimates; ground measurements; irradiation maps; Djibouti; Sub-Saharan Africa

Words (without nomenclature and section "Acknowledgments"):

- Words in text $=6338$

- Words in headers $=170$

- Words outside text (captions, etc.) $=167$

\section{Nomenclature}

A TOA albedo

$a, a^{\prime}, b, b^{\prime}$ constant parameters depending on the aerosol type

${ }^{*}$ Corresponding author

Email addresses: benjaminfp@unisinos.br (Benjamin Pillot), marc .muselli@univ-corse.fr (Marc Muselli), philippe.poggi@univ-corse.fr (Philippe Poggi), joaobd@unisinos.br (João Batista Dias) 


\begin{tabular}{|c|c|}
\hline$A_{c}$ & cloud albedo \\
\hline$A_{s}$ & surface albedo \\
\hline$A_{\text {ray }}$ & Rayleigh albedo \\
\hline$B$ & narrowband to broadband conversion coefficient \\
\hline$C$ & radiometer count \\
\hline$c_{1}, c_{2}$ & SEVIRI calibration coefficients $\left.\left(\mathrm{mW} \mathrm{m}{ }^{-2} \mathrm{sr}^{-1}\left(\mathrm{~cm}^{-1}\right)^{-1}\right)\right)$ \\
\hline$E_{0}$ & solar constant $\left(1367 \mathrm{~W} / \mathrm{m}^{2}\right)$ \\
\hline$F_{0}$ & effective solar constant $\left(\mathrm{W} / \mathrm{m}^{2}\right)$ \\
\hline$f_{\text {aniso }}$ & anisotropy factor \\
\hline$G$ & global horizontal radiation $\left(\mathrm{W} / \mathrm{m}^{2}\right)$ \\
\hline$G_{0}$ & extraterrestrial radiation on a horizontal plane $\left(\mathrm{W} / \mathrm{m}^{2}\right)$ \\
\hline$j$ & day of the year \\
\hline$k_{t}$ & clearness index \\
\hline$L$ & radiance measured by SEVIRI visible channel $\left(\mathrm{W} \mathrm{m}^{-2} \mathrm{sr}^{-1}\right)$ \\
\hline$L_{s c}$ & scale radiance \\
\hline$M$ & narrowband to broadband conversion coefficient \\
\hline$m$ & cloud absorption factor \\
\hline$m_{0}$ & day fraction corresponding to the local noon \\
\hline$m_{1}$ & sunrise day fraction \\
\hline$m_{2}$ & sunset day fraction \\
\hline$n$ & sample size \\
\hline$R$ & broadband reflectance \\
\hline$R_{n b}$ & narrowband reflectance \\
\hline$T_{1}$ & sun-surface transmittance without multiple scattering \\
\hline$T_{2}$ & sun-cloud-satellite transmittance \\
\hline$T_{a}$ & clear sky transmittance \\
\hline$T_{c}$ & cloud transmittance \\
\hline$T_{2}^{\prime}$ & sun-surface-satellite transmittance \\
\hline
\end{tabular}




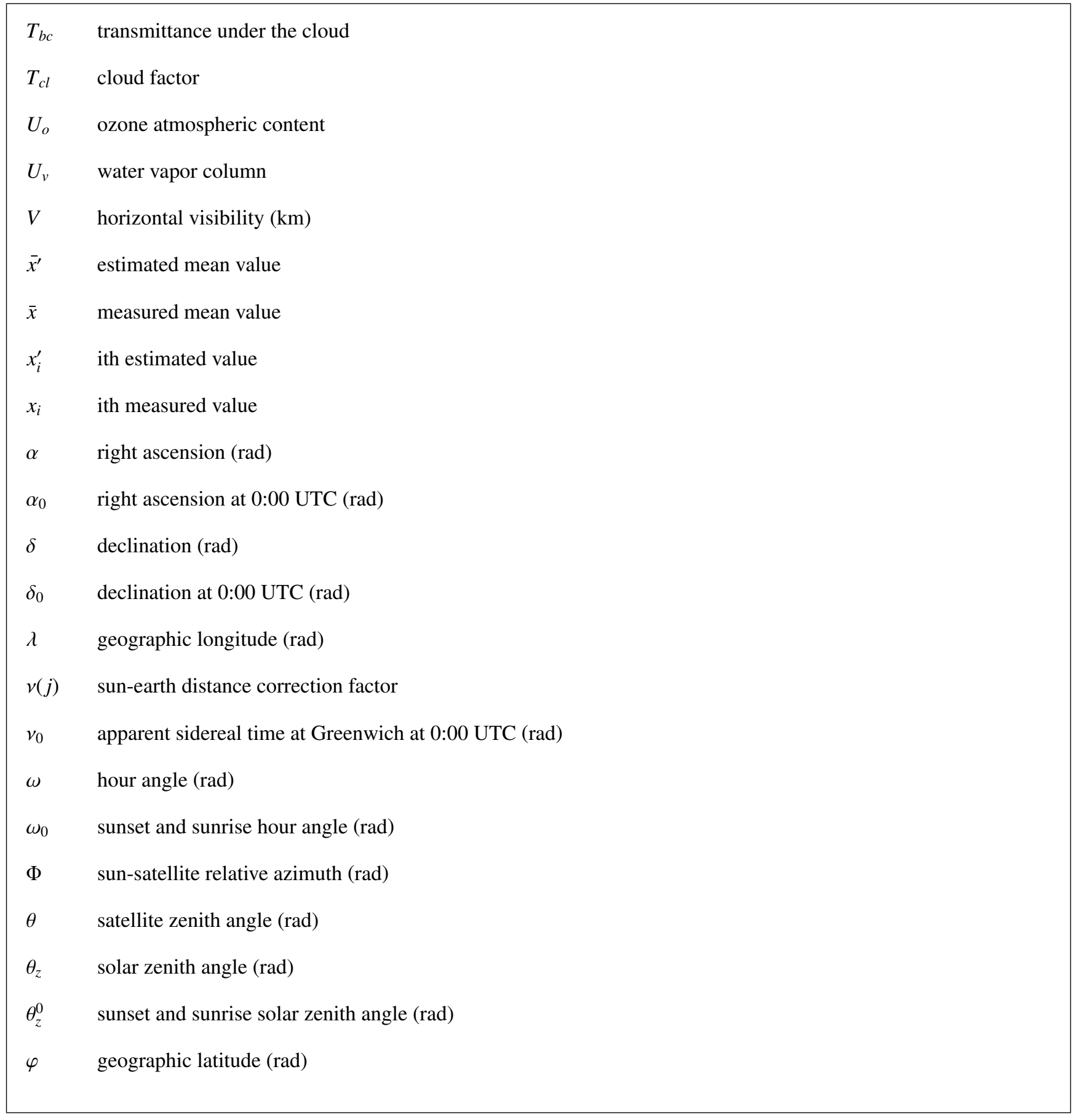

\section{Introduction}

Today, energy supply, as water access, of rural populations is one of the most important challenges in African developing countries, and more particularly in Sub-Saharan Africa. While about $68 \%$ of the Sub-Saharan population is living in rural 4 areas, the electrification rate of these populations is thus still only about $15 \%$ (Birol, 2011). In addition, many recurrent power 
supply utility crisis have occurred and are still occurring in African countries (Karekezi, 2002). Therefore, these countries have above all to stabilize their existing electrical grid, while expanding the network in order to reach small and dispatched isolated areas presents apparent technical and economical limitations (Karekezi and Kithyoma, 2002). Meanwhile, classical standalone energy supply solutions present important restrictions. Indeed, oil prices have been persistently increasing for many years (British Petroleum, 2014) and the massive use of remote resources, as fuel-wood, often destroys environment dramatically and causes severe socioeconomic troubles (Bugaje, 2006). Obviously, this specific energy supply layout has dramatic consequences. As these remote populations can't get out of poverty without any difficulties, most of them end up moving around urban centers, crowding with other rural migrants into suburban shantytowns. As a result of this background, African governments have been looking for alternative power systems. Among them, renewable energies offer a reliable profile for an economical and sustainable development, especially for rural and isolated populations (Bugaje, 2006; Deichmann et al., 2011; Karekezi, 2002; Karekezi and Kithyoma, 2002). As Africa presents important renewable resources (Bugaje, 2006), the integration of these energies is part of the main policies across the continent (Chineke and Ezike, 2010; Karekezi, 2002).

Although the Republic of Djibouti is one of the smallest African countries $\left(23200 \mathrm{~km}^{2}\right)$, located in the Horn of Africa, it summarizes the African energy supply challenge. In 2010, the electrical production was around $340 \mathrm{GWh}$ and the total installed power of the electrical grid is, at present time, about $125 \mathrm{MW}$ (Électricité De Djibouti, 2015). The low available power $(\approx 60 \%)$ produces high instability in the electricity distribution, and the very low coverage rate of the electrical network (about $30 \%$ ) leaves many people scattered throughout the country without any energy (Ahmed Aye, 2009). At last, vegetation only covers $70000 \mathrm{Ha}$ of the land area $(\approx 3 \%)$ and is mainly composed of very sparse timber resources, which restrains energy supply alternatives for remote rural populations (Daher Robleh, 2007). Energy supply is thereby one of the primary aims of the government's policy in the Republic of Djibouti. However, the integration of renewable energy into the energy scheme is still low (about $0.2 \%$ of the total installed power), even though large geothermal and solar potentials are actually available (Ahmed Aye, 2009). Between these 2 resources, power systems relying on solar energy present many interesting standalone applications, including, for instance, Solar Home Systems (SHS) (Wamukonya, 2007), solar thermal electrification (Odeh et al., 2003) or solar cooking as an alternative to the use of fuel and fuel-wood (Abu-Malouh et al., 2011; Ahmed Aye, 2009; Wentzel and Pouris, 2007). The solar resource can therefore be regarded as a reliable way for sustaining economic development and reducing the poverty of rural people. Nonetheless, energy supply planning of remote populations by using solar systems also requires to know accurately the solar resource and its geographic distribution over the country, i.e. to develop a solar potential mapping intended to evaluate the significance of the resource and its adequacy with the location of remote populations.

Accordingly, this work presents the first solar potential analysis in the Republic of Djibouti, based on satellite estimates from year 2008 to year 2014. Indeed, if satellite-based radiation data are theoretically more precise than an extrapolation of ground measurements (Muselli et al., 1998; Perez et al., 1997), they are also very valuable in Africa, where few ground solar data are available (Diabate et al., 2004), and where existing solar potential studies remain limited (Drake and Mulugetta, 1996; Madhlopa, 2006). At present time, in Djibouti, there are no existing data as well as any pyranometer or meteorological network (Ahmed Aye, 2009), and the deployment of a modern pyranometer network is economically, technically and safely 
limited. For these reasons, we have considered the use of a satellite-based model, which is today a very reliable way to assess solar radiation (Paulescu et al., 2013; Zelenka et al., 1999). Eventually, in order to evaluate the accuracy of the final radiation estimates, we have retrieved in-situ data by installing 2 temporary weather stations in 4 different locations across the country, between 2010 and 2013.

This article is composed of 4 parts. The first one introduces the satellite-derived model we have used in this study, the Surface Solar Irradiance (SSI) model developed by the Ocean \& Sea Ice Satellite Application Facility (OSI SAF) depending on the European Organisation for the Exploitation of Meteorological Satellites (EUMETSAT). The second one describes the entire process we have implemented to produce the final solar radiation maps. The third one depicts the accuracy assessment work, which has consisted in the deployment of a temporary meteorological network in the country and in a statistical comparison between radiation estimates and ground measurements. Finally, the last part presents the first yearly and monthly mean maps of the daily irradiation reaching the ground between 2008 and 2014.

\section{The OSI SAF satellite-derived radiation model}

\subsection{The OSI SAF SSI model}

Many satellite-based radiation models have been developed over the last years (Paulescu et al., 2013), and all of them, whether the Heliosat model (Beyer et al., 1996; Rigollier, 2004) or the ones developed by Zelenka et al. (1999), Perez et al. (2002) or Janjai et al. (2005), require data collected by geostationary orbital satellites. In this study, the satellite series covering the Djibouti's area has been launched by EUMETSAT, an intergovernmental European organization specialized in the processing of climate and meteorological satellite data. In order to take benefit from the expertise of each member states, this organization also relies on a network of 8 Satellite Application Facilities (SAF), each one based on the cooperation between several services and led by a national meteorology office (Guevel, 2005). As one of the main research topics of the OSI SAF consortium is the surface solar radiation modeling and because it is hosted by the french institute Météo-France, which is directly connected to the University of Corsica by a scientific agreement, the radiation estimates produced by the SSI model this service has developed were therefore directly available to us. That's why we have instigated the use of this specific satellite-based model.

\subsection{The MSG satellite series}

Current data used by OSI SAF to develop its products are related to the satellite series of the Meteosat Second Generation (MSG), a program established by EUMETSAT in cooperation with the European Space Agency (ESA). The SSI model data we have used in this work are based on the specific MSG-2 and MSG-3 satellites (Schmetz et al., 2002).

The satellite is nominally located over the equator at $0^{\circ}$ longitude, and the image acquisition is achieved by the Spinning Enhanced Visible and Infrared Imager (SEVIRI) instrument located aboard. This image radiometer operates from the visible spectrum ( 2 channels) to the infrared ( 9 channels), with one available high-resolution broadband channel retrieving data into the $0.4 \mu \mathrm{m}-1.1 \mu \mathrm{m}$ spectrum. The entire Earth image disk retrieved by channels 1 to 11 has a $3712 \times 3712$ resolution, from 


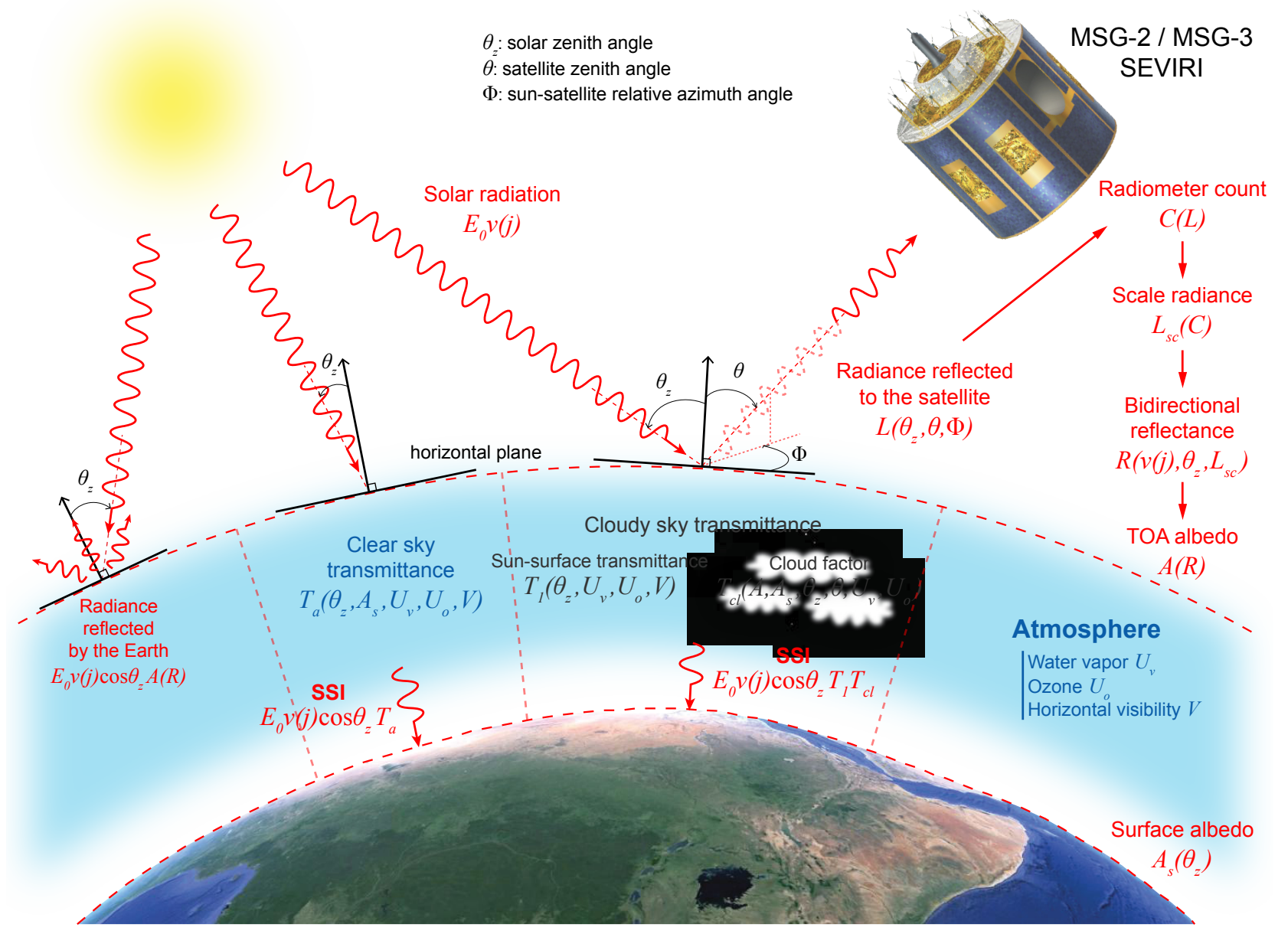

Figure 1: Detailed description of the SSI process developed by the OSI SAF.

$3 \mathrm{~km}$ at nadir to about $5 \mathrm{~km}$ near Djibouti (Müller, 2010; Schmetz et al., 2002). The nominal acquisition cycle of an image by SEVIRI lasts 15 minutes and consists in scanning, for 12 minutes, the Earth disk, line by line, from east to west and south to north, and in calibrating and retracing to its initial position the scan mirror (3 minutes).

\subsection{The SSI procedure}

The SSI production process has been completely operational since July 2004, and resulting irradiance data are available under given conditions via the OSI SAF website (http://www.osi-saf.org). Also, this model has been assessed and validated against ground measurements in many locations throughout the world (Le Borgne et al., 2005; Le Borgne et al., 2006) and is widely described in a literature intended to final users (Brisson et al., 1999; Météo-France, 2005). We therefore only present here the main steps of the complete process described in Figure 1. 


\subsubsection{Basic principle}

The SSI model is a physical parameterization which, when applied to every pixel of a satellite image, allows retrieving the instantaneous global horizontal solar radiation reaching the earth surface in the $0.3-4 \mu \mathrm{m}$ solar spectrum (Brisson et al., 1999). This model typically estimates the multiple diffusion, absorption and reflection effects of the radiation with a clear or cloudy atmosphere to finally determine the atmospheric transmittance. Knowing perfectly the extraterrestrial or Top of Atmosphere (TOA) irradiance, it is therefore possible to evaluate the net solar flux reaching the ground on a horizontal plane or SSI.

To model interaction of the solar radiation with atmosphere, the SSI process is based on previous studies where atmosphere is divided in 2 layers in order to dissociate scattering effects occurring in the clear sky and in the cloud layer (Frouin and Chertock, 1992). As a result, the global solar radiation reaching the ground $G$, or SSI, can be expressed by the product between the TOA radiation $G_{0}$, the clear sky transmittance $T_{a}$ and the cloud transmittance $T_{c}$ (Darnell et al., 1988; Pinker et al., 1995):

$$
G=G_{0} T_{a} T_{c}
$$

Brisson et al. (1999) have adapted this model by differentiating clear sky and cloudy sky cases:

$$
\begin{cases}G=G_{0} T_{a} & \text { in clear case } \\ G=G_{0} T_{1} T_{c l} & \text { in cloudy case }\end{cases}
$$

Where $T_{1}$ is the sun-surface atmospheric transmittance without multiple reflections between the surface and the lower layers of the atmosphere (consistent with $T_{a}$ ), and $T_{c l}$ is the cloud factor taking into account all the effects resulting of the interaction of the radiation with the cloud layer (transmittance and multiple reflections).

\subsubsection{SSI time and spatial resolution}

The SSI procedure is based on images acquired every hour by SEVIRI. The 12 minutes of the radiometer image scanning, line by line, also result in a specific time shift between the beginning of the acquisition and the effective line acquisition by SEVIRI. This gap evolves linearly with the line position within the satellite image (Météo-France, 2011) and is approximately equal to 470 seconds over Djibouti.

Furthermore, satellite images are spatially reprojected on a regular grid by means of a weighted average of the surface contribution of each original satellite pixel to the total surface of the final SSI pixel (Météo-France, 2005). The same method is also applied to every parameter used in the model and retrieved from data having different spatial resolution. If the spatial resolution of this grid was $0.1^{\circ}$ until 2011, it is important to note the OSI SAF database has been completely revised during the year 2012, improving the resolution from $0.1^{\circ}$ to $0.05^{\circ}$ (Météo-France, 2013).

Therefore, as all the methods presented here remain exactly the same for both the resolutions, final results of this work are presented with the new current resolution $\left(0.05^{\circ}\right)$, and $0.1^{\circ}$ SSI pixels from the period 2008-2011 have just been disaggregated onto the new $0.05^{\circ}$ regular grid. 


\subsubsection{TOA solar radiation on a horizontal plane}

The TOA or extraterrestrial radiation on a horizontal plane is directly derived from the solar flux normal to a surface at the top of the atmosphere, given for a specific sun-earth distance (1 astronomical unit), and called solar constant. The World Meteorological Organization (WMO) recommends to take the following value (Li et al., 2011):

$$
E_{0}=1367 \mathrm{~W} / \mathrm{m}^{2}
$$

Therefore, the solar radiation reaching the Earth for any day of the year is retrieved by performing the product of the solar constant and the sun-earth distance correction factor $v(j)$, which only depends on the Julian day $j$ :

$$
v(j)=1+0.0334 \cos \left[\frac{2 \pi(j-2)}{365.25}\right]
$$

At last, the TOA solar radiation on a horizontal plane $G_{0}$ represents the solar flux $E_{0} v(j)$ reaching a horizontal surface with a specific zenith angle $\theta_{z}$, angle between the local zenith and the radiation direction:

$$
G_{0}=E_{0} v(j) \cos \theta_{z}
$$

\subsubsection{Clear sky transmittance}

In order to differentiate the clear sky from the cloudy sky transmittance computation, a final SSI pixel is regarded as clear or cloudy depending on its cloudiness. The cloud cover is determined according to the classification developed by the Nowcasting and very short range SAF (NWC SAF), available at satellite resolution (Derrien et al., 2013). The clear sky procedure is finally applied when the cloud cover is lower than $10 \%$.

The clear sky transmittance calculation is independent from the satellite observation and is directly derived from the analytic formula proposed by Frouin et al. (1989), which considers water vapor and ozone absorption, gas and aerosol diffusion, and multiple reflections between the ground and the lower atmospheric layers (backscattering). It depends on atmospheric water vapor $U_{v}$ and ozone $U_{o}$ quantities, derived from monthly database and meteorological model prediction, on the horizontal visibility $V$ computed from the latitude and the month (Stuhlmann et al., 1990), on the surface albedo $A_{s}$ and on the optical path $1 / \cos \theta_{z}$ :

$$
T_{a}=\frac{\overbrace{\exp \left(-0,102\left(U_{v} / \cos \theta_{s}\right)^{0,29}\right) \exp \left(-0,041\left(U_{o} / \cos \theta_{s}\right)^{0,57}\right)}^{\text {absorption }} \overbrace{\exp \left(-(a+b / V) / \cos \theta_{s}\right)}^{\text {diffusion }}}{\underbrace{1-A_{s}\left(a^{\prime}+b^{\prime} / V\right)}_{\text {backscattering }}}
$$

$a, b, a^{\prime}$ and $b^{\prime}$ are constant parameters depending on the aerosol type. The surface albedo $A_{s}$ varies with the solar zenith angle $\theta_{z}$ (Briegleb et al., 1986); it is derived from a monthly atlas for "land" pixels and theoretically calculated for "sea" pixels, which will later explain some results of the comparison with ground measurements. 


\subsubsection{Cloudy sky transmittance}

The cloudy sky transmittance computation consists in determining the cloud factor $T_{c l}$, which is computed with respect to the planetary or TOA albedo retrieved from the satellite measure. Every pixel of the satellite image is a 8 bits digital count which is converted in a radiance value using specific calibration coefficients (Brisson et al., 1999). At present time, measurements are realized by the VISO.6 visible channel of SEVIRI $(0.56-0.71 \mu \mathrm{m})$, and the physical measure of the scaled radiance $L_{s c}$ is linearly derived from the satellite count $C$ (Météo-France, 2005; Müller, 2010):

$$
L_{s c}=c_{1}+c_{2} C
$$

$c_{1}$ and $c_{2}$ are SEVIRI visible channel specific coefficients. The scaled radiance $L_{s c}$ corresponds to the radiance $L$ measured by the visible channel of SEVIRI divided by the solar constant convoluted with the radiometer's spectral response $F_{0}$ :

$$
L_{s c}=\frac{L \pi}{F_{0}}
$$

$F_{0} v(j) \cos \theta_{z}$ represents therefore the TOA irradiance on a horizontal plane in the SEVIRI channel spectrum, so the spectral response specific reflectance or narrowband reflectance $R_{n b}$ is given by:

$$
R_{n b}=\frac{L \pi}{F_{0} v(j) \cos \theta_{z}}=\frac{L_{s c}}{v(j) \cos \theta_{z}}
$$

The broadband reflectance $R$, corresponding to the whole solar spectrum $(0.3-4 \mu \mathrm{m})$, is then derived from the Pinker and Laszlo (1992) formula:

$$
R=M R_{n b}+B
$$

Where $M$ and $B$ are specific coefficients depending on the pixel's surface and cloudiness. $R$ is bidirectional, which means it depends on both sun and satellite's viewing angle, defined by the solar zenith angle $\theta_{z}$, the satellite zenith angle $\theta$ and the sun-satellite relative azimuth angle $\Phi$. The TOA albedo $A$ is retrieved by correcting this anisotropy with the anisotropy factor $f_{\text {aniso }}$ developed by Manalo-Smith et al. (1998), which is pixel's surface and cloudiness dependent:

$$
A\left(\theta_{z}\right)=\frac{R\left(\theta_{z}, \theta, \Phi\right)}{f_{\text {aniso }}\left(\theta_{z}, \theta, \Phi\right)}
$$

${ }_{48}$ Finally, the cloud factor $T_{c l}$ is expressed as the product of a transmittance term $T_{c}$, representing absorption and reflection by the cloud, by a backscattering term $1 /\left(1-T_{b c} A_{s} A_{c}\right)$ modeling the multiple reflections between the cloud base and the earth surface (Brisson et al., 1994):

$$
T_{c l}=\frac{T_{c}}{1-T_{b c} A_{s} A_{c}}
$$


The backscattered part depends on the surface albedo $A_{s}$, the cloud albedo $A_{c}$ and the atmospheric transmittance under the cloud $T_{b c}$ regarded as constant. The transmittance $T_{c}$ is directly derived from the cloud albedo and the cloud absorption factor $m$ which is considered constant:

$$
T_{c}=1-A_{c}-A_{c} m \cos \theta_{z}
$$

The cloud albedo is derived from the planetary albedo which takes into account the fraction of the incident radiation reflected by the clear atmosphere (Rayleigh albedo $A_{\text {ray }}$ ), the one reflected by the cloud cover $\left(A_{c}\right)$ and the one reflected by the surface $\left(A_{s}\right)$. As it is also dependent on the atmospheric transmittance and the backscattering effect, the TOA albedo is finally defined by the following expression (Brisson et al., 1994, 1999):

$$
A=A_{\text {ray }}+T_{2}^{\prime} A_{c}+\frac{T_{2} T_{c}^{2}}{1-T_{b c} A_{s} A_{c}} A_{s}
$$

$T_{2}$ and $T_{2}^{\prime}$ are respectively the sun-cloud-satellite transmittance and the sun-surface-satellite transmittance computed like the transmittance $T_{1}$ using the formalism of Brisson et al. (1994). The resolution of this equation permits to retrieve $A_{c}$ and $T_{c}$, and thus the cloud factor $T_{c l}$ from the relation (12).

\subsubsection{Final SSI maps}
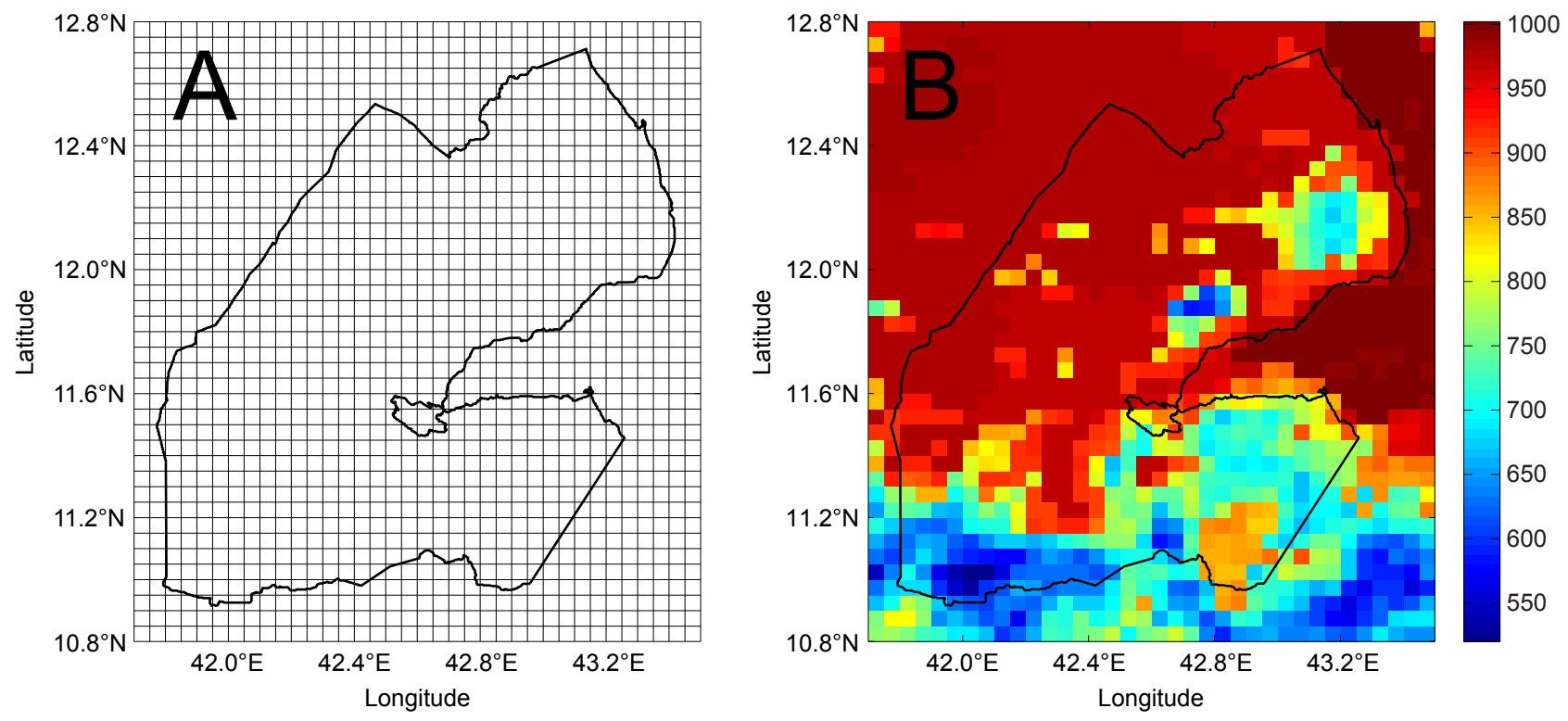

Figure 2: Regular $0.05^{\circ}$ grid currently used for SSI reprojection (A) and example of solar radiation map (W/m²) for the 03/12/2013 10:07:50 UTC (B) over the Republic of Djibouti.

The final SSI product is an hourly map of the instantaneous solar radiation $\left(\mathrm{W} / \mathrm{m}^{2}\right)$ in regular geographic coordinates $\left(0.1^{\circ}\right.$ 
$80^{\circ}$ (Météo-France, 2005). Figure 2 shows the current SSI reprojection regular grid and an irradiance map example using the new resolution.

\section{Implementation of a solar irradiation atlas}

We describe here the method we have used to build the solar atlas of Djibouti, a database of the hourly solar irradiation maps of the country between 2008 and 2014.

\subsection{The solar atlas of Djibouti: from static mapping description to local dynamic use}

The solar atlas of the Republic of Djibouti is a spatiotemporal dataset composed of solar energy maps derived from hourly SSI maps produced by the OSI SAF model. The purpose of this tool is thus to be used in a global to local approach where a static analysis of the geographic distribution of the solar resource leads to local dynamic modeling of solar power systems. Essentially, in order to analyze the level of the resource across the country, it is possible to extract some tendencies from the atlas by summing up an average data over monthly and yearly periods. Then, solar potential time series from the atlas can be used to size and model solar systems within the most relevant areas.

Furthermore, if the SSI maps released by the OSI SAF are only instantaneous observations, it is more relevant to know the resource in a quantitative way, like fossil resources, i.e. as solar energy reaching the ground $\left(\mathrm{Wh} / \mathrm{m}^{2}\right)$ rather than solar irradiance $\left(\mathrm{W} / \mathrm{m}^{2}\right)$. Therefore, we have preferred this approach by integrating the solar radiation to retrieve the global solar irradiation on a horizontal plane.

\subsection{Time resolution and processing time period}

The time resolution of the solar atlas was directly dependent of the SSI time step, so we have developed an atlas composed of hourly irradiation maps.

The specific solar climate tendency we can extract from the atlas also depends on which time period the database is retrieved for: an interval too short doesn't allow to cover all climate notable features, while an interval too long can also average current climate attributes with the past ones, possibly different because, for instance, of global warming. If the elementary unit is necessarily the tropical year corresponding to the seasonal cycle (Meeus and Savoie, 1992), which allows to record all the main climate fluctuations, the time period was also dependent in our case on other heavy post processes (Pillot, 2014). Therefore, in order to keep the current climate variations up to date, we have opted for the period 2008-2014, resulting in solar maps with the new $0.05^{\circ}$ spatial resolution. At last, to maintain consistency over the atlas, solar maps at $0.1^{\circ}$ from 2008 to 2011 have been reprojected onto the $0.05^{\circ}$ regular grid by means of a simple disaggregation.

\subsection{Interpolation of missing data within SSI maps}

\subsubsection{Invalid, erroneous and missing SSI data}

SSI data are not calculated or erroneous when the solar zenith angle is greater than $80^{\circ}$, when the NWC SAF cloud classification is missing, when an internal error occurs during the cloud factor computation or when the estimation of the TOA 
albedo is outside the interval corresponding to $T_{c l}=0$ and $T_{c l}=1$ (Météo-France, 2005). Moreover, some data were simply missing, probably because of errors during the OSI SAF computation process. As a result, before retrieving solar irradiation maps, it was firstly necessary to implement an interpolation method in order to fill in SSI original maps.

\subsubsection{Use of the clearness index}

The interpolation we have implemented is specific to each type of error, is based on classical time or spatial interpolation techniques, but above all is not directly applied to the SSI data. Indeed, the model only determines atmospheric transmittance (equation (2)), which means interpolating the solar radiation $G$ would be interpolating on both the transmittance and the TOA radiation $G_{0}$ even though this last one is perfectly known (equation (5)). In order to avoid adding a bias into the calculation, we have therefore considered the interpolation of only the transmittance terms $T_{a}$ and $T_{1} T_{c l}$, by using the clearness index $k_{t}$ (Lorenzo, 2003):

$$
k_{t}=G / G_{0}
$$

\subsubsection{Determination of the extraterrestrial solar radiation}

The computation of the TOA radiation with relation (5) requires to know the corresponding solar zenith angle $\theta_{z}$. The formula allowing to retrieve this angle in local or topocentric coordinates is now well-known (Lorenzo, 2003; Meeus, 1998) and only the final accuracy can differ. That's why we have used the sun position algorithm developed by the National Renewable Energy Laboratory (NREL) intended to compute the angle with a $\pm 0.0003^{\circ}$ uncertainty (Meeus, 1998; Reda and Andreas, 2008). This process estimates the sun local coordinates from its position on the ecliptic within the celestial sphere at a moment of the year, defined by the declination $\delta$ and the right ascension $\alpha$. The sun position during the day is then derived from the hour angle $\omega$, angle between the local earth meridian and the sun celestial meridian. Finally, the solar zenith angle is assessed by the following well-known equation (Lorenzo, 2003; Meeus, 1998; Reda and Andreas, 2008):

$$
\cos \theta_{z}=\sin \varphi \sin \delta+\cos \varphi \cos \delta \cos \omega
$$

Where $\varphi$ is the geographic latitude. By combining equations (5) and (16), it is therefore possible to retrieve the TOA radiation $G_{0}$ for every pixel of all of the SSI maps.

\subsection{Retrieving global solar irradiation}

By recalculating the global horizontal radiation from the now interpolated clearness index database and the TOA radiation, it is then possible to compute the new solar irradiation map database using integration. In order to achieve that, it is also necessary to know the daily boundaries of the solar irradiance, i.e. the sunrise and sunset corresponding times. 


\subsubsection{Computation of sunrise and sunset times}

Sunrise and sunset have been retrieved by using the NREL algorithm (Reda and Andreas, 2008), which firstly consists in determining the local solar noon. The day fraction $m_{0}$ corresponding to the time when the sun is located on the local meridian is given by:

$$
m_{0}=\frac{\alpha_{0}-\lambda-v_{0}}{360}
$$

Where $\alpha_{0}$ is the right ascension and $v_{0}$ the apparent sidereal time at Greenwich at 0:00 UTC, and $\lambda$ the geographic longitude. Also, the corresponding hour angle $\omega_{0}$ is retrieved using equation (16) and the declination at 0:00 UTC $\delta_{0}$ :

$$
\omega_{0}=\arccos \left(\frac{\cos \theta_{z}^{0}-\sin \varphi \sin \delta_{0}}{\cos \varphi \cos \delta_{0}}\right)
$$

Where $\theta_{z}^{0}$ is the solar zenith angle corresponding to the sun position at sunrise and sunset, considered equal to $90.8333^{\circ}$ because of atmospheric refraction (Meeus, 1998; Reda and Andreas, 2008).

At last, sunrise and sunset day fractions $m_{1}$ and $m_{2}$ are calculated by subtracting or adding the time lapse corresponding to the hour angle $\left(\omega_{0} / 360\right)$ to $m_{0}$ :

$$
\begin{aligned}
& m_{1}=m_{0}-\frac{\omega_{0}}{360} \\
& m_{2}=m_{0}+\frac{\omega_{0}}{360}
\end{aligned}
$$

\subsubsection{Integration of SSI data}

Integration of the global radiation $G$ between sunrise and sunset times leads to the global irradiation $I$. From a numerical point of view, it is important to interpolate the clearness index between the SSI original points before retrieving $I$, in order to improve the integration final accuracy. Example results are described in Figure 3, where daily irradiation is thus the total area under the $G$ curve and hourly irradiation the area of each part located between integer hours.

\section{Ground assessment of the Republic of Djibouti's solar irradiation maps}

In order to evaluate the accuracy of the whole procedure, we have statistically compared the final irradiation estimates with ground measurements realized from 2010 to 2013. Because of the lack of radiation measurements in the country as well as any validation studies of the OSI SAF model in the region, we have deployed a temporary weather station network throughout the Republic of Djibouti in collaboration with the Centre d'Études et de Recherche de Djibouti (CERD), the country's national science institute. 


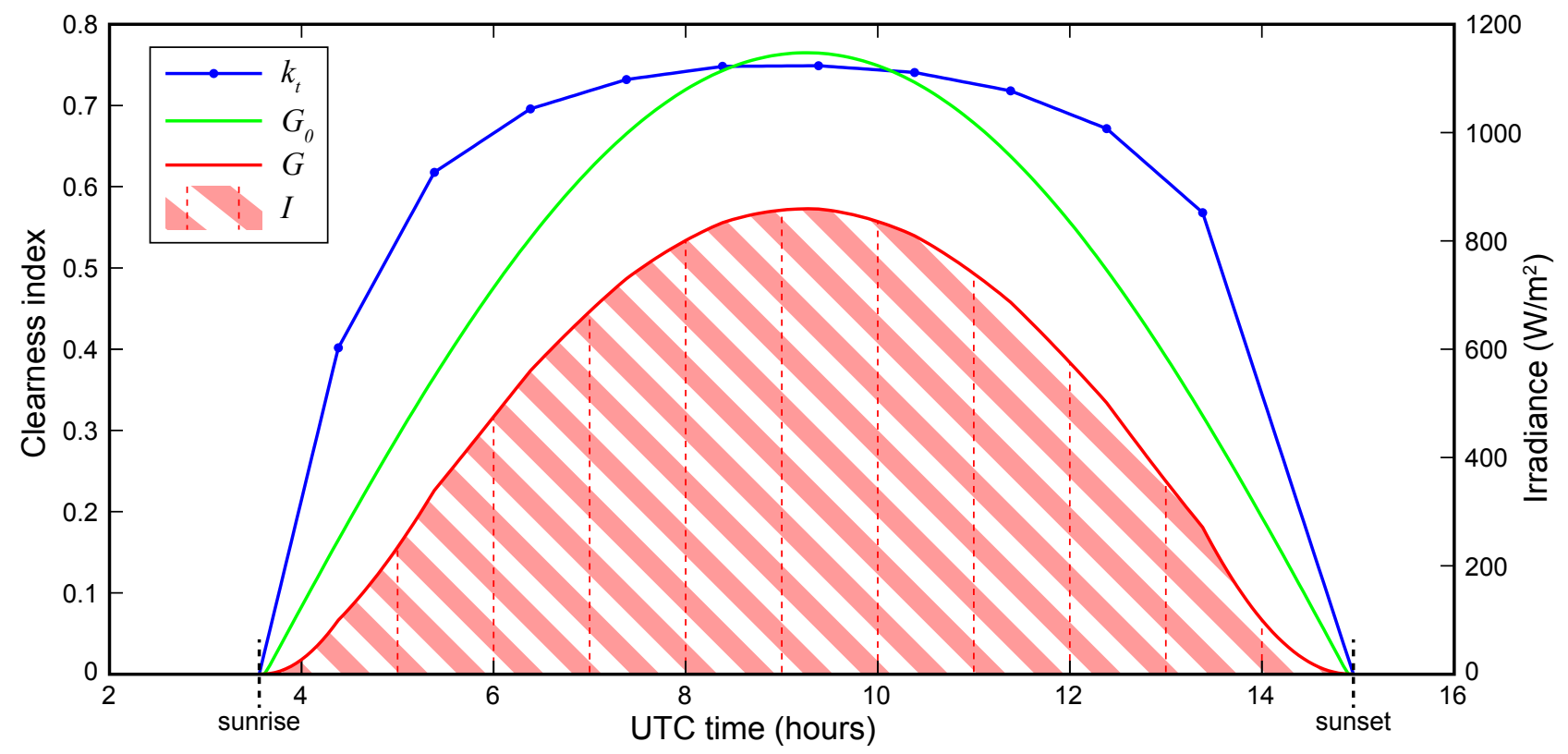

Figure 3: Clearness index $k_{t}$ linearly interpolated between OSI SAF model original points and TOA radiation $G_{0}$ from which is estimated global radiation $G$. Hourly and daily irradiation $I$ is retrieved by integrating $G$ between sunrise and sunset.

\subsection{Deploying a temporary network of weather stations}

The quality of the solar irradiation atlas is directly dependent of SSI data computed by the OSI SAF model. The validation campaign of this model against ground measurements has relied on a pyranometer network presenting a very heterogeneous geographical coverage (Le Borgne et al., 2006). Validation stations were indeed mainly located over mid and high latitudes (Europe and North America), few of them over low latitudes and equator (Antilles and French Guyana) and only one in the southern hemisphere (South Africa). With no available ground data in Djibouti until now, it was therefore essential to achieve our own measurements in order to evaluate consistency of both the SSI model and final solar atlas.

Thus, in 2010, we set up 2 Davis Instruments weather stations in the country with the help of the CERD, and moved them on other locations in 2012. Every station was equipped with standard sensors as well as a silicon-based pyranometer measuring global horizontal solar irradiation with a $\pm 5 \%$ accuracy. If this kind of pyranometer is still less accurate than thermopile pyranometers (Sengupta et al., 2012), it is nevertheless important to note that the calibration of these sensors has been widely improved over the last years (King et al., 1998; King and Myers, 1997) and also that we have only measured irradiation and not irradiance, limiting therefore possible biases. Furthermore, this technology has firstly been made necessary because of economic, logistic and safety requirements. Cost, security of equipment, difficult access to the different regions or device maintenance because of adverse weather conditions (dust storms, aerosols) were indeed limitations to the implementation of high-quality pyranometers.

In order to select the weather station implantation sites, we had to follow different requirements. Firstly, it was important to choose sites corresponding to SSI pixels substantially distant from each other to ensure irradiance estimates were sufficiently 
different and so not correlated (Perez et al., 1997). Then it was logistically necessary to keep the material safe and also easily accessible (no data transmission), which means we had to target at public facilities like schools or administrative buildings. We have finally selected 4 sites meeting these conditions, which are described by Figure 4 and detailed in Table 1. Both the stations were primarily implanted in Djibouti-city and Dikhil in 2010, and then moved to Ali Sabieh and the Day Forest in January 2012. At last, all the sites present a relatively good geographic dispersion and also cover the Djibouti's altitude range $([0 ; 2000 \mathrm{~m}])$.

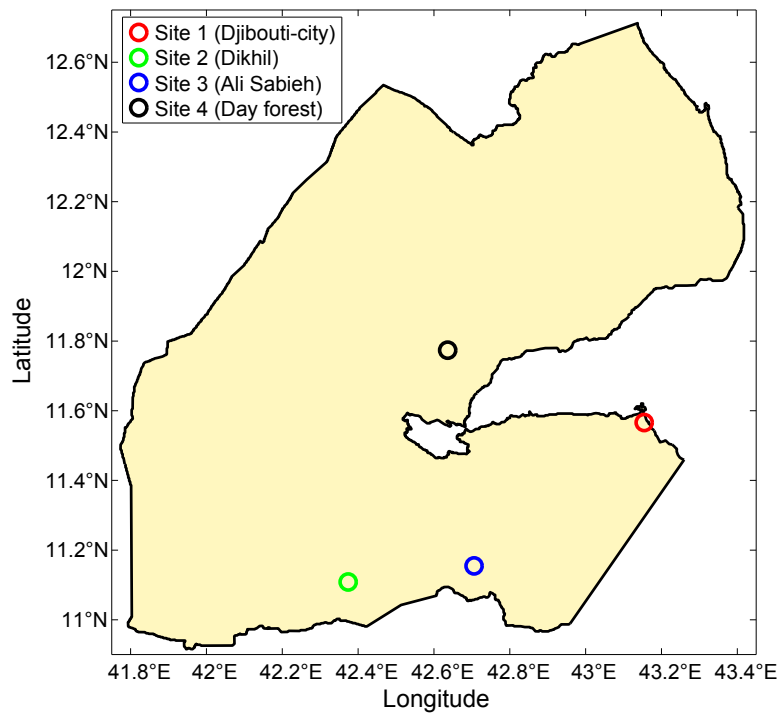

Figure 4: Location of the 4 sites where the 2 temporary weather stations have been installed between 2010 and 2013 .

Table 1: Coordinates of the 4 weather station sites.

\begin{tabular}{lccrr}
\hline & Location & Latitude & Longitude & Altitude \\
\hline Site 1 & Djibouti & $11.5658^{\circ} \mathrm{N}$ & $43.1543^{\circ} \mathrm{E}$ & $7 \mathrm{~m}$ \\
Site 2 & Dikhil & $11.1087^{\circ} \mathrm{N}$ & $42.3736^{\circ} \mathrm{E}$ & $498 \mathrm{~m}$ \\
Site 3 & Ali Sabieh & $11.1546^{\circ} \mathrm{N}$ & $42.7060^{\circ} \mathrm{E}$ & $718 \mathrm{~m}$ \\
Site 4 & Day forest & $11.7734^{\circ} \mathrm{N}$ & $42.6362^{\circ} \mathrm{E}$ & $1576 \mathrm{~m}$ \\
\hline
\end{tabular}

\subsection{Estimates vs measurements: methodology and results}

In order to evaluate the accuracy of the solar atlas, we have considered SSI pixels overlapping the weather station locations and performed a statistical analysis between estimates and corresponding in situ measurements. 


\subsubsection{Methodology}

Global irradiation has been measured by pyranometers of each weather station with a specific time step depending on the accessibility level of the material's location: 5 minutes for site 1, 10 minutes for sites 2 and 3, and 1 hour for site 4 . The measurements were carried out respectively from $04 / 09 / 2010$ to 12/17/2011 and from 06/27/2010 to 12/05/2011 for sites 1 and 2 , then from 01/09/2012 to 05/01/2013 and from 01/07/2012 to 10/02/2012 for sites 3 and 4 .

The irradiation data retrieved during this campaign have been then computed, checked and reprocessed if necessary to finally only keep the ones where days didn't present any missing data between theoretical sunrise and sunset, in order to avoid adding a bias into the further correlation coefficient calculation. As the comparison has been realized on hourly, daily and monthly data, it was indeed relevant to keep consistency between all the data by only considering hourly measurements corresponding to daily ones. Also, missing measurements have mainly resulted from 3 error types: a technical failure during data transmission between the station emitter and the data acquisition receiver, a no data recovery, or a human error during data manipulation with the acquisition software. Eventually, the resulting proportion of missing daily measurements for each time period was respectively equal to $10.84 \%, 25.62 \%, 9.81 \%$ and $7.39 \%$ for sites $1,2,3$ and 4 .

We have considered 2 different approaches to compute the estimates: an analysis of the SSI model through the solar atlas (original dataset), where the SSI dataset has been limited to daily intervals without any erroneous, missing or not calculated SSI values, and an analysis of the solar irradiation atlas itself (interpolated dataset). In the first case, we have therefore retrieved irradiation by integrating radiation between the first and last computed SSI data of the day. In the second case, which allows assessing impact of the clearness index interpolation onto the final consistency of the solar atlas, estimates have been derived from the whole interpolated SSI database by integrating radiation between sunrise and sunset (see section 3.4.2).

Because of the relative limited measurement period and the inherent structure of the solar atlas, we have based our statistical comparison on 3 different time steps: hour, day and month. The first one is directly related to the time step of the solar irradiation maps, and the second and third ones allow to figure out the quality of the solar cartography presented in the next section. Hourly and daily irradiation data have been retrieved as previously described, and monthly irradiation has been computed by summing the corresponding daily values over months at least composed of 20 effective days, i.e. days where both measurements and estimates were existing, in order to avoid adding a bias into the correlation coefficient computation. In the same way, hourly measurements have been retrieved from meteorological data corresponding to the time period of the estimates, and then summed to recover daily and monthly values.

According to Iqbal (1983) and Notton et al. (2004), in order to assess accuracy of both the OSI SAF model and our final solar atlas over the Republic of Djibouti, we have based our comparison study on the use of 3 well-known statistical indicators, the root mean square error (RMSE), the mean bias error (MBE) and the correlation coefficient (CC): 


$$
\begin{aligned}
\mathrm{RMSE} & =\sqrt{\frac{\sum_{i=1}^{n}\left(x_{i}^{\prime}-x_{i}\right)^{2}}{n}}\left(\mathrm{Wh} / \mathrm{m}^{2}\right) \\
\mathrm{MBE} & =\sqrt{\frac{\sum_{i=1}^{n}\left(x_{i}^{\prime}-x_{i}\right)}{n}}\left(\mathrm{Wh} / \mathrm{m}^{2}\right) \\
\mathrm{CC} & =\frac{\sum_{i=1}^{n}\left(x_{i}-\bar{x}\right)\left(x_{i}^{\prime}-\overline{x^{\prime}}\right)}{\sqrt{\sum_{i=1}^{n}\left(x_{i}-\bar{x}\right)^{2} \sum_{i=1}^{n}\left(x_{i}^{\prime}-\overline{x^{\prime}}\right)^{2}}}
\end{aligned}
$$

As well as their relative contribution, respectively the relative root mean square error (RRMSE) and the relative mean bias error (RMBE):

$$
\begin{aligned}
\mathrm{RRMSE} & =\mathrm{RMSE} / \bar{x}(\%) \\
\mathrm{RMBE} & =\mathrm{MBE} / \bar{x}(\%)
\end{aligned}
$$

Where $x_{i}$ is the ith measured value, $x_{i}^{\prime}$ the ith estimated value, $\bar{x}$ the measured mean value, $\bar{x}^{\prime}$ the estimated mean value and $n$ the sample size.

\subsubsection{Results}

Table 2 presents the results of the statistical comparison between estimates and measurements of the global horizontal irradiation, for every site and time step. Besides that, it is important to note that estimates from sites 1 and 2 correspond to the old SSI spatial resolution $\left(0.1^{\circ}\right)$ while estimates from sites 3 and 4 correspond to the new one $\left(0.05^{\circ}\right)$ implemented in 2012 (see section 2.3.2).

This table aggregates all values of the 5 statistical indicators we have previously defined, computed on all of the 3 time steps used for irradiation data comparison. About that, since daily irradiation is computed by summing hourly values, RMBE is therefore the same for both the samples. Furthermore, monthly comparison obviously presents the lowest error and the highest correlation for all sites, but as the samples are more limited, we will mainly focus on the daily and hourly results, and keep the monthly time step as a climate indicator for scatter plots described later.

Globally, we can note that:

- the best results are retrieved for the site 2 with, daily and hourly respectively, a maximum RRMSE of $5.98 \%$ and $12.38 \%$ and a minimum correlation coefficient of 0.9300 and 0.9566 ;

- the daily relative error is still lower or equal to $8 \%$ while the daily correlation coefficient is still greater or equal to 0.89 ;

- if the hourly correlation is approximately constant for all the sites, sites 2 and 4 present better daily correlation than sites 1 and 3; 
Table 2: Comparison between estimated and measured global horizontal irradiation data.

\begin{tabular}{|c|c|c|c|c|c|c|c|c|}
\hline Site & SSI dataset & Time step & Sample & $\begin{array}{r}\text { RMSE } \\
\left(\mathrm{Wh} / \mathrm{m}^{2}\right)\end{array}$ & $\begin{array}{r}\text { RRMSE } \\
(\%)\end{array}$ & $\begin{array}{r}\mathrm{MBE}^{1} \\
\left(\mathrm{Wh} / \mathrm{m}^{2}\right)\end{array}$ & $\begin{array}{r}\mathrm{RMBE}^{1} \\
(\%)\end{array}$ & $\mathrm{CC}$ \\
\hline \multirow{7}{*}{1} & & month & 17 & 5630.0 & 3.76 & -1070.5 & -0.71 & 0.9662 \\
\hline & original & day & 537 & 431.0 & 7.99 & -57.4 & -1.06 & 0.8954 \\
\hline & & hour & 4616 & 80.2 & 12.79 & -6.7 & -1.06 & 0.9307 \\
\hline & & & & & & & & \\
\hline & & month & 17 & 6777.5 & 4.15 & -2408.7 & -1.48 & 0.9616 \\
\hline & interpolated & day & 548 & 468.3 & 8.05 & -103.1 & -1.77 & 0.8962 \\
\hline & & hour & 7213 & 67.7 & 15.31 & -7.8 & -1.77 & 0.9771 \\
\hline \multirow{7}{*}{2} & & month & 12 & 6830.3 & 4.40 & 3822.0 & 2.46 & 0.9689 \\
\hline & original & day & 384 & 331.9 & 5.98 & 136.4 & 2.46 & 0.9337 \\
\hline & & hour & 3289 & 66.2 & 10.21 & 15.9 & 2.46 & 0.9566 \\
\hline & & & & & & & & \\
\hline & & month & 13 & 6500.4 & 3.90 & 2319.4 & 1.39 & 0.9718 \\
\hline & interpolated & day & 391 & 343.9 & 5.72 & 81.7 & 1.36 & 0.9300 \\
\hline & & hour & 5099 & 57.0 & 12.38 & 6.3 & 1.36 & 0.9857 \\
\hline \multirow{7}{*}{3} & & month & 15 & 9779.6 & 6.27 & 6072.8 & 3.89 & 0.9733 \\
\hline & original & day & 430 & 441.4 & 7.99 & 211.1 & 3.82 & 0.9146 \\
\hline & & hour & 3574 & 77.3 & 11.63 & 25.4 & 3.82 & 0.9403 \\
\hline & & & & & & & & \\
\hline & & month & 15 & 9380.5 & 5.48 & 4139.1 & 2.42 & 0.9607 \\
\hline & interpolated & day & 430 & 447.9 & 7.38 & 143.2 & 2.36 & 0.8892 \\
\hline & & hour & 5631 & 64.7 & 13.97 & 10.9 & 2.36 & 0.9827 \\
\hline \multirow{7}{*}{4} & & month & 6 & 4447.2 & 2.70 & 817.8 & 0.50 & 0.9926 \\
\hline & original & day & 212 & 440.4 & 7.66 & 37.5 & 0.65 & 0.9443 \\
\hline & & hour & 2035 & 90.3 & 15.08 & 3.9 & 0.65 & 0.9419 \\
\hline & & & & & & & & \\
\hline & & month & 6 & 4670.1 & 2.74 & 760.1 & 0.45 & 0.9916 \\
\hline & interpolated & day & 212 & 458.3 & 7.70 & 33.1 & 0.56 & 0.9420 \\
\hline & & hour & 2743 & 78.3 & 17.04 & 2.6 & 0.56 & 0.9719 \\
\hline
\end{tabular}

\footnotetext{
${ }^{1}$ A negative bias means model underestimation.
}

- the model slightly overestimates irradiation for sites 2,3 and 4 and slightly underestimates irradiation for site 1 ;

- interpolation performed to fill erroneous and missing data in the original SSI dataset doesn't strongly modifies accuracy. 
Furthermore, the increase of the hourly correlation coefficient, as well as the decrease of the bias, is not really relevant since it is mainly related to the growth of estimates near sunrise and sunset.

Not as good results for sites 1, 3 and 4 as for site 2 can be explained by more frequent cloudiness, linked with a still low spatial and time resolution of the OSI SAF model. This cloudiness can for example result from coastline proximity or also, especially for sites 3 and 4, from their location within mountains. Moreover, when the Intertropical Convergence Zone (ITCZ) crosses the country between June and September, the atmospheric aerosol concentration also increases because of the sandy wind called Khamsin (Ahmed, 2001), and can be different from one region to another. At last, unlike other ones, site 1 corresponds to a SSI pixel where surface is both "land" and "sea", which can also influence the accuracy of the surface albedo into transmittance calculation (see section 2.3.4).

Scatter plots corresponding to the whole solar atlas (interpolated dataset) are presented in Figure 5. They confirmed the previous results with a globally good correlation and accuracy between estimates and in situ measurements, where the scatter plot of site 2 is therefore the less dispersed around the 1:1 line for every time step. In addition to the table, we can note that, besides site 4 , the model mainly overestimates high irradiation values (midday, clear skies) and underestimates low values (beginning and end of day, cloudy skies). Eventually, despite the climate temporal variability shown by the monthly diagrams, it is interesting to note that estimates still remain consistent with the ground data.

\subsubsection{Comparison with other studies and models}

If no assessment studies of the SSI model have ever been realized over the Horn of Africa, the different validation campaigns achieved by the OSI SAF over mid and low latitudes have nearly presented the same results, but by analyzing irradiance (Le Borgne et al., 2005; Le Borgne et al., 2006, 2007). Thereby, for the year 2004, daily and hourly relative error was respectively equal to $8.6 \%$ and $16.7 \%$ and the bias was positive but irrelevant $(\approx+2 \%)$. The 2006 campaign over equatorial Atlantic, near Djibouti's latitude, has exposed hourly RRMSE, RMBE and correlation coefficient between $12.9 \%$ and $22.4 \%$, $3.5 \%$ and $9.5 \%$, and 0.947 and 0.969 respectively. Finally, the study performed from January 2004 to April 2006, over a very large dataset, has produced daily and hourly relative errors of $8.7 \%$ and $17 \%$, and a negligible positive bias.

Compared to other satellite-derived models like Heliosat and Heliosat-2 (Beyer et al., 1996; Rigollier, 2004), the atlas globally presents lower error and correlation. Thus, according to the literature reviewed by Rigollier (2004), Heliosat has presented a relative daily error between $9 \%$ and $16 \%$ for different sites in Europe, North America, Brazil and Sahel, and a hourly error between $14 \%$ and $30 \%$ for Europe. Furthermore, the comparison achieved by the same authors between Heliosat2 estimates and ground measurements from 35 stations in Europe has given the following results: a daily (respectively hourly) RRMSE equal to $10 \%$ (18\%) in July and equal to $20 \%$ (45\%) in January, and a daily (respectively hourly) correlation coefficient between 0.94 and 0.95 (0.83 and 0.9). An other Heliosat-2 study realized in a similar climate has also been achieved in Iran by Moradi et al. (2009). Daily comparison with the Yazd's arid climate has shown a relative error of $9.9 \%$ and a determination coefficient of 0.905 . 
(a)
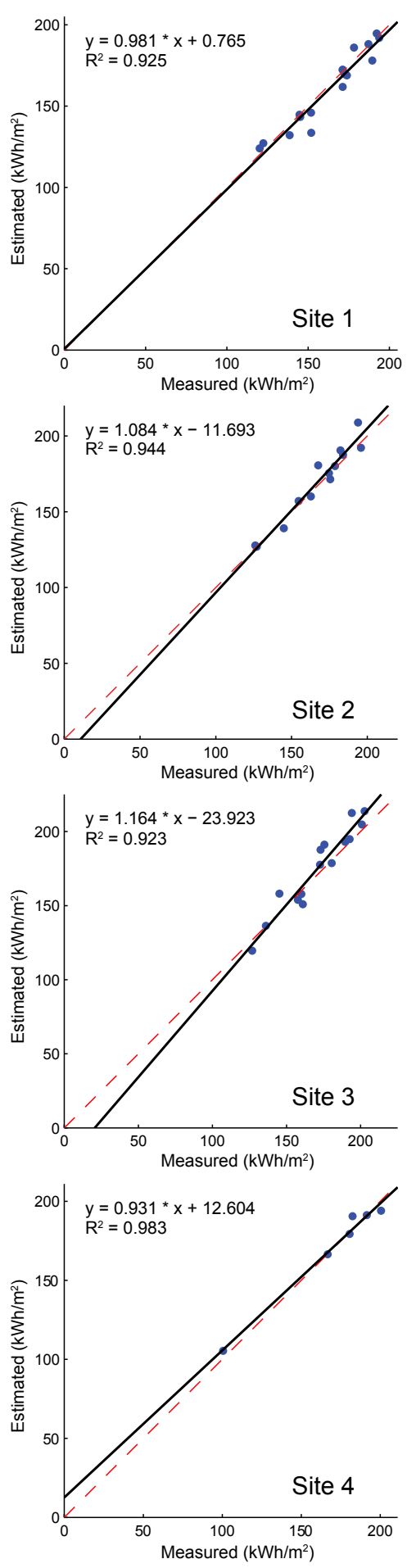

(b)
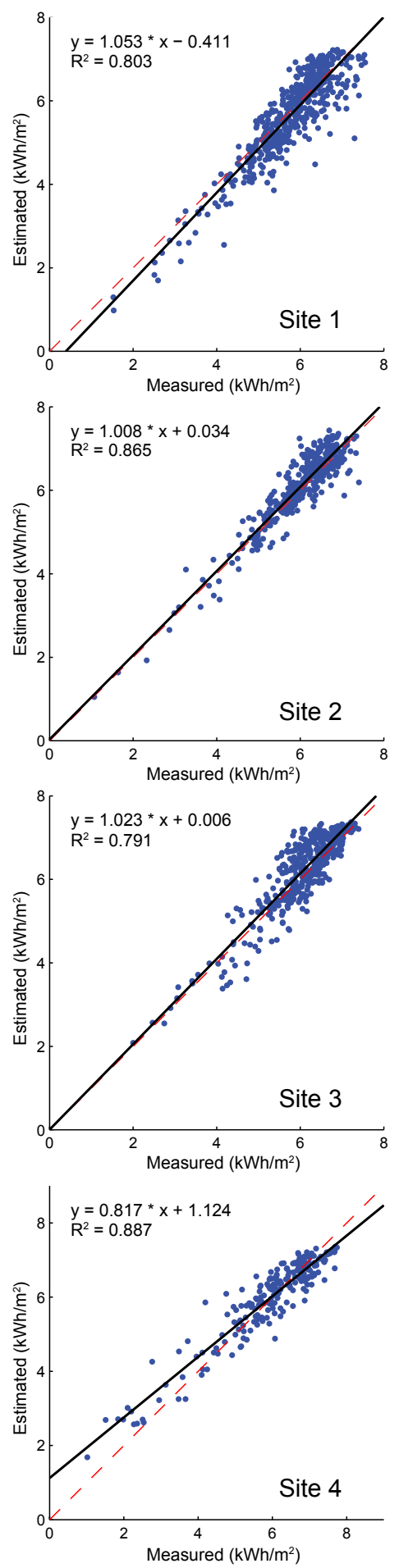

(c)
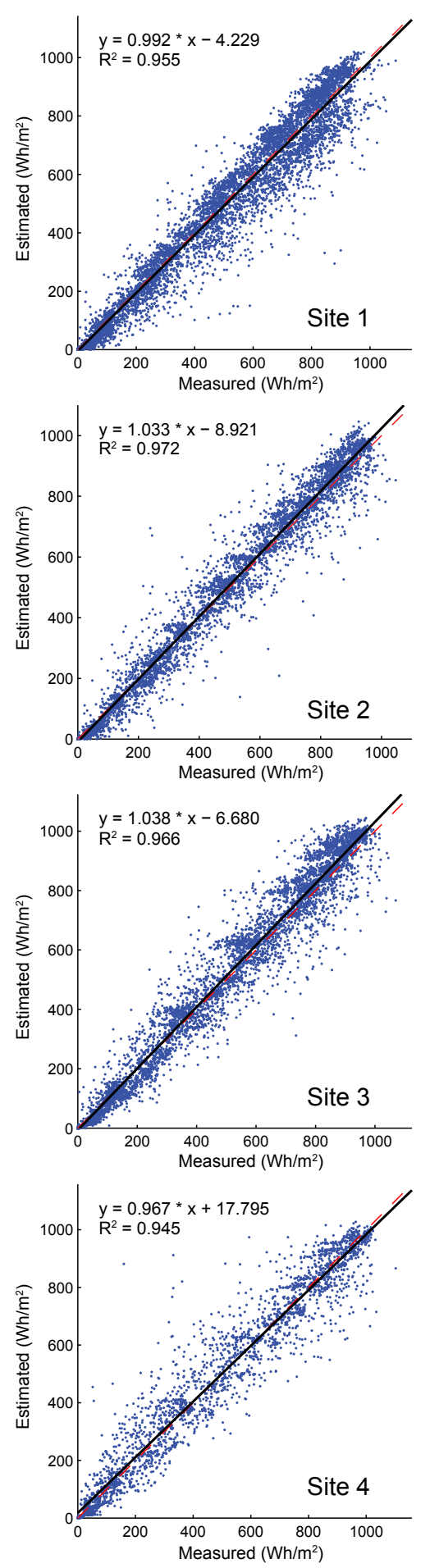

Figure 5: Monthly (a), daily (b) and hourly (c) estimated against measured global irradiation scatter plots, with regression line (black) and its equation, 1:1 line (red dotted) and determination coefficient. 


\subsubsection{Conclusion}

Essentially, the OSI SAF model has allowed to develop a solar irradiation atlas with an accuracy as good as the one available for other regions, and other existing models, in the same kind of climate or not, have not shown such good results, with higher error and similar correlation coefficient. Thus, even if spatial and temporal resolutions of the OSI SAF model could be improved, this model was enough to accurately estimate solar irradiation in a country such as Djibouti where optimal weather conditions exist.

\section{Solar irradiation maps of the Republic of Djibouti}

As described in section 3.1, the solar atlas of the Republic of Djibouti consists in a hourly database of solar irradiation maps. In order to extract some tendencies about the solar resource in the country, it is possible to compute the average irradiation reaching the ground over some specific time periods. We therefore present here monthly and yearly maps of the daily mean irradiation as well as their main characteristics.

\subsection{Methodology}

Because of the apparent motion of the sun around the Earth, the year is the period of a climate cycle. In order to figure out the solar irradiation behavior over a specific area, it is therefore necessary to evaluate the resource over several years and extract a typical year by averaging over the resulting sample (Lorenzo, 2003). The typical mapping format used into the literature is the daily mean irradiation (Cogliani et al., 2008; Janjai et al., 2011; Martins et al., 2007), probably because as the basic solar cycle (nyctohemeral period) it allows to compare tendencies of different time periods (week, month, year). We have therefore computed here monthly means and yearly mean of daily global irradiation, in order to respectively observe the temporal evolution of the solar resource and quantify the resource. Finally, we have performed a spatial statistical analysis on the resulting irradiation maps, by only processing irradiation reaching the ground within the country boundaries.

\subsection{Results: mapping of the daily mean irradiation}

Figure 6 shows the yearly mean level of the daily solar irradiation available in the Republic of Djibouti, while Figure 7 presents the monthly evolution of the resource. Finally, Table 3 aggregates different statistical indicators extracted from these maps, including irradiation range, mean and standard deviation as well as the land fraction where a specific amount of solar energy is available.

Firstly, the yearly map tells us the solar resource is globally substantial and also relatively consistent throughout the country, which is confirmed by the high average $\left(5.92 \mathrm{kWh} / \mathrm{m}^{2}\right.$ day $)$ and the low standard deviation $\left(0.216 \mathrm{kWh} / \mathrm{m}^{2}\right.$ day $)$. Comparison with other studies (Janjai et al., 2011; Martins et al., 2007) or with the theoretical yearly irradiation reaching the Earth's surface (NASA, 2013) exhibits the available solar energy across the country is indeed at the top of the world resource. Moreover, we can note the region is split into 2 distinct solar potential zones: on the one hand, the south-east and north-east of the country on each side of the gulf, and on the other hand, western of Djibouti from the Ghoubbet bay. This separation 


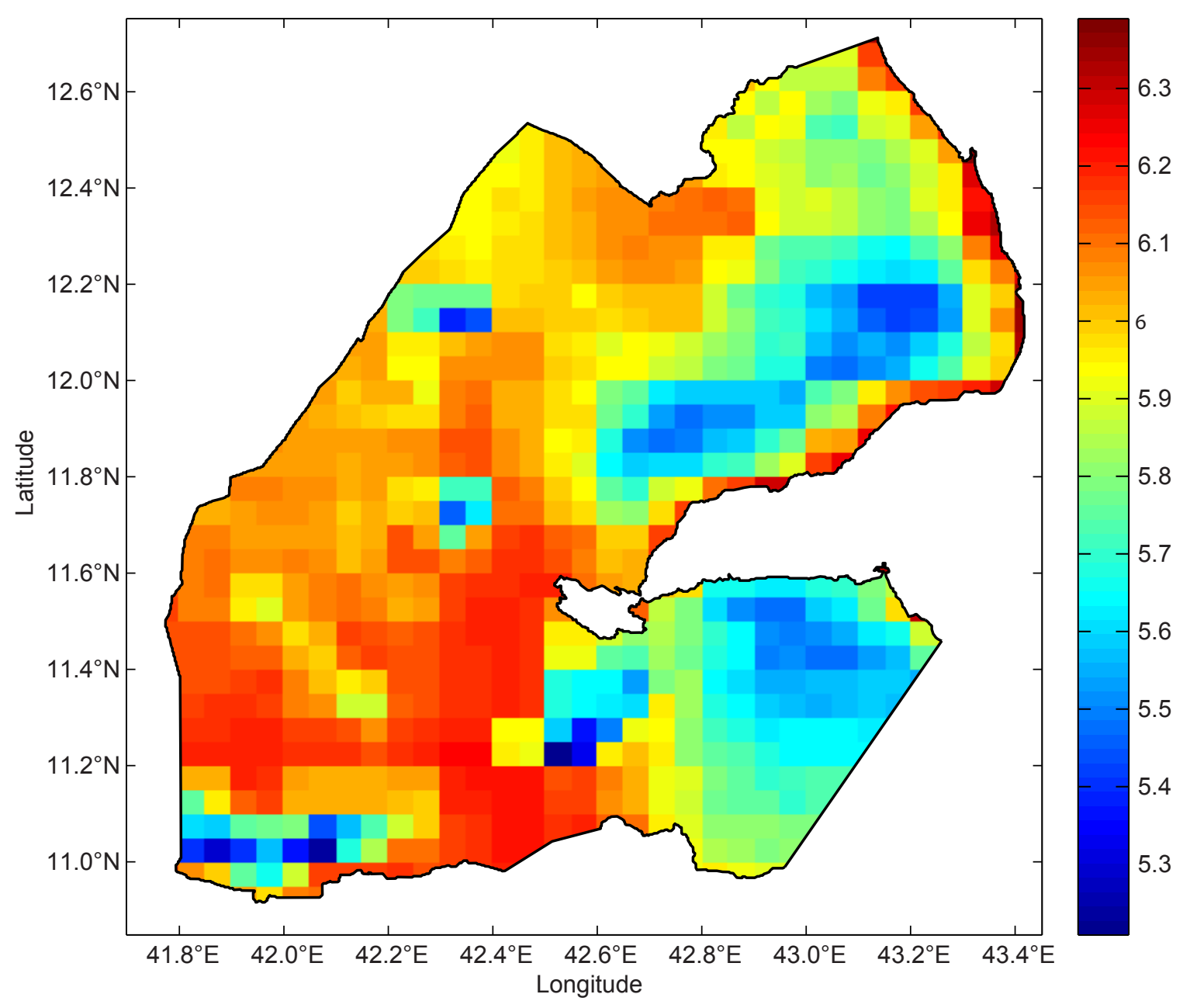

Figure 6: Yearly map of the daily mean irradiation $\left(\mathrm{kWh} / \mathrm{m}^{2}\right.$ day) over the Republic of Djibouti.

is also visible in Table 3 where $38 \%$ of the country is receiving daily irradiation between $5.1 \mathrm{kWh} / \mathrm{m}^{2}$ and $5.9 \mathrm{kWh} / \mathrm{m}^{2}$, and $62 \%$ between $5.9 \mathrm{kWh} / \mathrm{m}^{2}$ and $6.6 \mathrm{kWh} / \mathrm{m}^{2}$.

Then, monthly maps and their characteristics give information about climate evolution over the year. Thus, when the sun's path is the lowest in the sky, from November to February, the solar resource is the lowest (mean irradiation between $5.08 \mathrm{kWh} / \mathrm{m}^{2}$ day and $5.66 \mathrm{kWh} / \mathrm{m}^{2}$ day) and the most variable (standard deviation between $0.28 \mathrm{kWh} / \mathrm{m}^{2}$ day and $0.54 \mathrm{kWh} / \mathrm{m}^{2}$ day). From March to May, when the sun is high, the potential is substantial and spatially consistent, between $6.40 \mathrm{kWh} / \mathrm{m}^{2}$ day and $6.69 \mathrm{kWh} / \mathrm{m}^{2}$ day. When the ICTZ crosses the country, from June to September, return of the Khamsin clearly reduces the potential, from $6.3 \mathrm{kWh} / \mathrm{m}^{2}$ day to $5.9 \mathrm{kWh} / \mathrm{m}^{2}$ day in July and August; in addition, the sandy wind also appears homogeneous across the country with a standard deviation lower than $0.2 \mathrm{kWh} / \mathrm{m}^{2}$ day from June to August. At last, monthly maps expose that to the both solar geographic zones are mixed 3 different 4-month solar periods over the year, from November to February, from March to June and from July to October. 

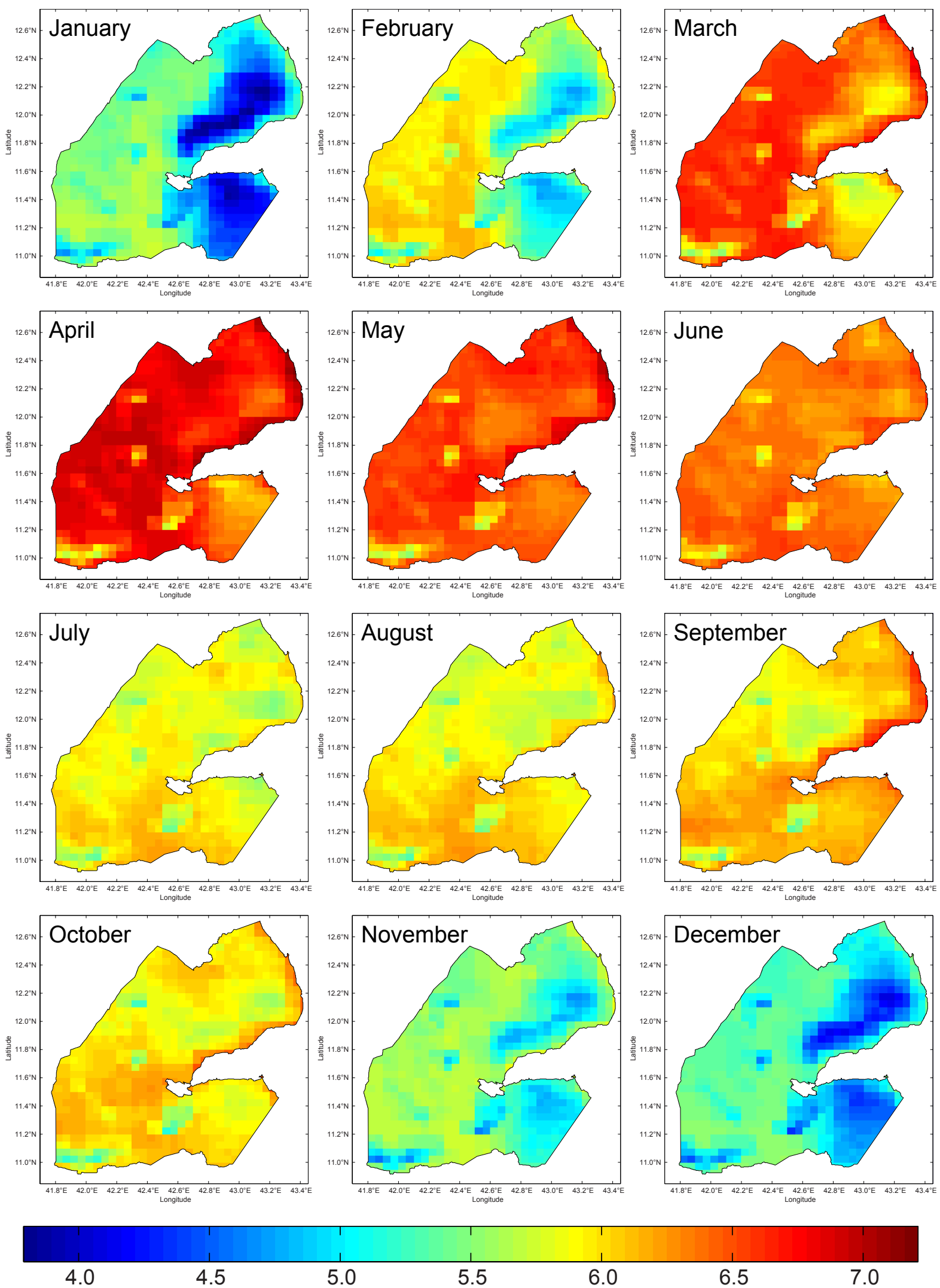

Figure 7: Monthly mean maps of the daily irradiation $\left(\mathrm{kWh} / \mathrm{m}^{2}\right.$ day) over the Republic of Djibouti. 
Table 3: Main characteristics of the Djibouti's daily mean irradiation maps.

\begin{tabular}{|c|c|c|c|c|c|c|c|c|}
\hline & \multicolumn{3}{|c|}{ Global irradiation $\left(\mathrm{kWh} / \mathrm{m}^{2}\right.$ day $)$} & \multicolumn{5}{|c|}{ Land fraction where irradiation is between ${ }^{1}(\%)$} \\
\hline & Range & Mean & Std & $3.7 \& 4.4$ & $4.4 \& 5.1$ & $5.1 \& 5.9$ & $5.9 \& 6.6$ & $6.6 \& 7.3$ \\
\hline January & $3.79-5.75$ & 5.08 & 0.540 & 16.2 & 24.9 & 58.8 & 0.0 & 0.0 \\
\hline February & $4.72-6.18$ & 5.66 & 0.403 & 0.0 & 14.2 & 40.7 & 45.2 & 0.0 \\
\hline March & $5.52-6.92$ & 6.40 & 0.281 & 0.0 & 0.0 & 7.1 & 59.7 & 33.2 \\
\hline April & $5.70-7.21$ & 6.69 & 0.255 & 0.0 & 0.0 & 0.9 & 26.0 & 73.1 \\
\hline May & $5.55-7.13$ & 6.50 & 0.185 & 0.0 & 0.0 & 1.5 & 74.8 & 23.6 \\
\hline June & $5.70-6.64$ & 6.34 & 0.131 & 0.0 & 0.0 & 1.3 & 98.5 & 0.2 \\
\hline July & $5.37-6.24$ & 5.89 & 0.153 & 0.0 & 0.0 & 50.5 & 49.5 & 0.0 \\
\hline August & $5.34-6.34$ & 5.92 & 0.166 & 0.0 & 0.0 & 45.9 & 54.2 & 0.0 \\
\hline September & $5.38-6.84$ & 6.07 & 0.203 & 0.0 & 0.0 & 18.8 & 80.0 & 1.2 \\
\hline October & $5.14-6.49$ & 5.96 & 0.182 & 0.0 & 0.0 & 32.0 & 68.0 & 0.0 \\
\hline November & $4.57-5.93$ & 5.40 & 0.279 & 0.0 & 18.9 & 81.1 & 0.0 & 0.0 \\
\hline December & $4.09-5.57$ & 5.09 & 0.362 & 5.6 & 36.1 & 58.3 & 0.0 & 0.0 \\
\hline Year & $5.21-6.39$ & 5.92 & 0.216 & 0.0 & 0.0 & 37.9 & 62.1 & 0.0 \\
\hline
\end{tabular}

${ }^{1}$ Range boundaries are given in $\mathrm{kWh} / \mathrm{m}^{2}$ day.

In conclusion, the irradiation reaching the country is particularly high, as well as spatially and temporally consistent. Furthermore, with a daily mean irradiation of $5.92 \mathrm{kWh} / \mathrm{m}^{2}$, the Republic of Djibouti is receiving about 20000 times the total energy consumed by the country in 2005 (Ahmed Aye, 2009).

\section{Conclusion}

If renewable energies can be used today in Sub-Saharan Africa to overcome the lack of energy supply of the rural populations, it is also necessary to precisely evaluate the available resource amount. In the Republic of Djibouti, previous studies have suggested a great potential of geothermal and solar resources (Ahmed Aye, 2009). If the first one can be regarded as an alternative for centralized power supply, the numerous standalone applications of solar energy make it really reliable for supplying rural areas. We have therefore developed a satellite-based solar atlas in order to assess both the significance and the spatiotemporal distribution of the solar resource throughout the country.

The lack of ground measurements has made necessary the use of a satellite-derived model. In this work, we have retrieved hourly irradiance maps between 2008 and 2014 at $0.05^{\circ}$ resolution from the SSI model implemented by the OSI SAF. By using a clearness index procedure, we have finally computed hourly irradiation maps of the country. Then, in order to evaluate 
accuracy of both the whole process and the irradiation maps, we have, on the one hand, carried out temporary weather stations over 4 different sites in the country to retrieve in situ data and, on the other hand, statistically compared estimates to these measurements.

Final results have shown good agreement between the solar atlas estimates and the ground measurements, according to the literature, with maximum daily and hourly relative errors of $8.05 \%$ and $17.04 \%$ and a minimum correlation of 0.8892 . Subsequently, monthly and yearly solar maps have exposed the country presents one of the most important potential in the world with a daily mean irradiation of $5.92 \mathrm{kWh} / \mathrm{m}^{2}$ day. The resource is moreover spatially and temporally consistent, presenting a spatial standard deviation equal to $0.216 \mathrm{kWh} / \mathrm{m}^{2}$ day and remaining between $5.08 \mathrm{kWh} / \mathrm{m}^{2}$ day and $6.69 \mathrm{kWh} / \mathrm{m}^{2}$ day over the year. Eventually, if this study confirms that solar potential is a valuable energy to supply the remote populations of the country, the resulting solar atlas has also to be regarded as a tool intended to help decision-makers in this future undertaking.

\section{References}

Abu-Malouh, R., Abdallah, S., Muslih, I. M., Jan. 2011. Design, construction and operation of spherical solar cooker with automatic sun tracking system. Energy Conversion and Management 52, 615-620.

Ahmed, M., 2001. Communication nationale initiale de la République de Djibouti à la Convention-cadre des Nations Unies sur les changements climatiques. Tech. rep., Ministère de l'habitat, de l'urbanisme, de l'environnement et de l'aménagement du territoire, Djibouti, République de Djibouti.

Ahmed Aye, F., Dec. 2009. Intégration des énergies renouvelables pour une politique énergétique durable à djibouti. Ph.D. thesis, Université de Corse.

Beyer, H. G., Costanzo, C., Heinemann, D., 1996. Modifications of the heliosat procedure for irradiance estimates from satellite images. Solar Energy 56 (3), 207 - 212.

Birol, F., 2011. World energy outlook 2011. Tech. rep., International Energy Agency - Office of the Chief Economist, Paris, France.

Briegleb, B. P., Minnis, P., Ramanathan, V., Harrison, E., 1986. Comparison of regional clear-sky albedos inferred from satellite observations and model computations. Journal of Climate and Applied Meteorology 25, 214-226.

Brisson, A., Borgne, P. L., Marsouin, A., Moreau, T., 1994. Surface irradiances calculated from Meteosat sensor data during SOFIA-ASTEX. International Journal of Remote Sensing 15 (1), 197-203.

Brisson, A., Le Borgne, P., Marsouin, A., 1999. Development of algorithms for surface solar irradiance retrieval at O\&SI SAF low and mid latitudes. Eumetsat Ocean and Sea Ice SAF internal project team report.

British Petroleum, 2014. BP statistical review of world energy. 
Bugaje, I. M., 2006. Renewable energy for sustainable development in africa: a review. Renewable and Sustainable Energy Reviews $10(6), 603-612$.

Chineke, T. C., Ezike, F. M., 2010. Political will and collaboration for electric power reform through renewable energy in africa. Energy Policy 38 (1), $678-684$.

Cogliani, E., Ricchiazzi, P., Maccari, A., 2008. Generation of operational maps of global solar irradiation on horizontal plan and of direct normal irradiation from meteosat imagery by using SOLARMET. Solar Energy 82 (6), 556 - 562.

Daher Robleh, Y., 2007. Rapport national sur l'état des ressources phytogénétiques pour l'alimentation et l'agriculture. Tech. rep., Ministère de l'agriculture, de l'élevage et de la mer chargé des ressources hydrauliques, Djibouti, République de Djibouti.

Darnell, W. L., Staylor, W. F., Gupta, S. K., Denn, F. M., Aug. 1988. Estimation of Surface Insolation Using Sun-Synchronous Satellite Data. Journal of Climate 1 (8), 820-836.

Deichmann, U., Meisner, C., Murray, S., Wheeler, D., Jan. 2011. The economics of renewable energy expansion in rural Sub-Saharan Africa. Energy Policy 39 (1), 215 - 227.

Derrien, M., Le Gléau, H., Fernandez, P., 2013. Product user manual for "cloud products". Support to Nowcasting and Very Short Range Forecasting Satellite Application Facility.

Diabate, L., Blanc, P., Wald, L., 2004. Solar radiation climate in africa. Solar Energy 76 (6), 733 - 744.

Drake, F., Mulugetta, Y., 1996. Assessment of solar and wind energy resources in ethiopia. I. Solar energy. Solar Energy $57(3), 205-217$.

Électricité De Djibouti, 2015. EDD website. http://www.edd.dj/index.html (access date: 05/10/2015).

Frouin, R., Chertock, B., 1992. A technique for global monitoring of net solar irradiance at the ocean surface. Part 1 : model. Journal of Applied Meteorology 31, 1056-1066.

Frouin, R., Lingner, D. W., Gautier, C., 1989. A simple analytical formula to compute clear sky total and photosynthetically available solar irradiance at the ocean surface. Journal of Geophysical Research 94 (C7), 9731-9742.

Guevel, G., Mar. 2005. The EUMETSAT ocean and sea ice SAF : Overview and status. In: SAF Training Workshop, Ocean and Sea Ice Second Workshop. Perros-Guirec, France.

Iqbal, M., 1983. An Introduction to Solar Radiation. Academic Press.

Janjai, S., Laksanaboonsong, J., Nunez, M., Thongsathitya, A., 2005. Development of a method for generating operational solar radiation maps from satellite data for a tropical environment. Solar Energy 78 (6), 739 - 751. 
Janjai, S., Pankaew, P., Laksanaboonsong, J., Kitichantaropas, P., Apr. 2011. Estimation of solar radiation over cambodia from long-term satellite data. Renewable Energy 36 (4), 1214-1220.

Karekezi, S., 2002. Renewables in Africa - meeting the energy needs of the poor. Energy Policy 30 (11-12), 1059-1069.

Karekezi, S., Kithyoma, W., 2002. Renewable energy strategies for rural Africa: is a PV-led renewable energy strategy the right approach for providing modern energy to the rural poor of sub-Saharan Africa? Energy Policy 30 (11-12), 1071 1086.

King, D. L., Boyson, W., Hansen, B., Bower, W., 6-10 July 1998. Improved accuracy for low-cost solar irradiance sensors. In: Proceedings of the 2nd World Conference and Exhibition on Photovoltaic Solar Energy Conversion. Vienna, Austria.

King, D. L., Myers, D. R., September 29 - October 3 1997. Silicon-photodiode pyranometers : Operational characteristics, historical experiences, and new calibration procedures. In: Proceedings of the 26th IEEE Photovoltaic Specialists Conference. Anaheim, California.

Le Borgne, P., Legendre, G., Marsouin, A., Mar. 2005. OSI SAF radiative fluxes. In: SAF Training Workshop, Ocean and Sea Ice Second Workshop. Perros-Guirec, France.

Le Borgne, P., Legendre, G., Marsouin, A., Jun. 2006. Validation of the OSI SAF radiative fluxes. In: Proceedings of the 2006 EUMETSAT Meteorological Satellite Conference. Helsinki, Finland.

Le Borgne, P., Legendre, G., Marsouin, A., Sep. 2007. Validation of the OSI SAF radiative fluxes over the equatorial atlantic during AMMA experiment. In: Proceedings of the 2007 EUMETSAT Meteorological Satellite Conference and the 15th Satellite Meteorology \& Oceanography Conference of the American Meteorological Society. Amsterdam, The Netherlands.

Li, H., Lian, Y., Wang, X., Ma, W., Zhao, L., 2011. Solar constant values for estimating solar radiation. Energy 36 (3), 1785 $-1789$.

Lorenzo, E., 2003. Energy collected and delivered by PV modules. In: Handbook of photovoltaic science and engineering, 1st Edition. John Wiley \& Sons, Chichester, U.K., Ch. 20, pp. 905-970.

Madhlopa, A., 2006. Solar radiation climate in malawi. Solar Energy 80 (8), 1055 - 1057.

Manalo-Smith, N., Smith, G., Tiwari, S., Staylor, W., 1998. Analytic forms of bidirectional reflectance functions for application to Earth radiation budget studies. Journal of Geophysical Research 103 (D16), 19 733-19 751.

Martins, F. R., Pereira, E. B., Abreu, S. L., 2007. Satellite-derived solar resource maps for Brazil under SWERA project. Solar Energy $81(4), 517-528$.

Meeus, J., 1998. Astronomical algorithms, 2nd Edition. Willmann-Bell, Richmond, USA.

Meeus, J., Savoie, D., 1992. The history of the tropical year. Journal of the British Astronomical Association 102 (1), $40-42$. 
Météo-France, 2005. Surface solar irradiance product manual. Ocean \& Sea Ice Satellite Application Facility.

Météo-France, 2011. Downwelling Surface Shortwave Flux (DSSF). Satellite Application Facility on Land Surface Analysis.

Météo-France, 2013. Geostationary radiative flux - product user manual. Ocean \& Sea Ice Satellite Application Facility.

Moradi, I., Mueller, R., Alijani, B., Kamali, G. A., 2009. Evaluation of the Heliosat-II method using daily irradiation data for four stations in Iran. Solar Energy 83 (2), 150 - 156.

Müller, J., 2010. MSG level 1.5 image data format description. Tech. rep., EUMETSAT, Darmstadt, Germany.

Muselli, M., Notton, G., Canaletti, J., Louche, A., 1998. Utilization of meteosat satellite-derived radiation data for integration of autonomous photovoltaic solar energy systems in remote areas. Energy Conversion and Management 39 (1), $1-19$.

NASA, 2013. Surface meteorology and solar energy release 6.0. https://eosweb.larc.nasa.gov/sse/ (access date: 05/10/2015).

Notton, G., Cristofari, C., Muselli, M., Poggi, P., Nov. 2004. Calculation on an hourly basis of solar diffuse irradiations from global data for horizontal surfaces in ajaccio. Energy Conversion and Management 45 (18-19), 2849-2866.

Odeh, S., Behnia, M., Morrison, G., Sep. 2003. Performance evaluation of solar thermal electric generation systems. Energy Conversion and Management 44, 2425-2443.

Paulescu, M., Paulescu, E., Gravila, P., Badescu, V., 2013. Solar radiation measurements. In: Weather Modeling and Forecasting of PV Systems Operation. Springer, London, U.K., Ch. 2.

Perez, R., Ineichen, P., Moore, K., Kmiecik, M., Chain, C., George, R., Vignola, F., 2002. A new operational model for satellite-derived irradiances: description and validation. Solar Energy 73 (5), $307-317$.

Perez, R., Seals, R., Zelenka, A., 1997. Comparing satellite remote sensing and ground network measurements for the production of site/time specific irradiance data. Solar Energy 60 (2), 89 - 96.

Pillot, B., 2014. Planification de l'électrification rurale décentralisée en Afrique subsaharienne à l'aide de sources renouvelables d'énergie : le cas de l'énergie photovoltaïque en République de Djibouti. Ph.D. thesis, Université de Corse.

Pinker, R., Frouin, R., Li, Z., 1995. A review of satellite methods to derive surface shortwave irradiance. Remote Sensing of Environment 51 (1), $108-124$.

Pinker, R., Laszlo, I., 1992. Modeling surface solar irradiance for satellite applications on global scale. Journal of Applied Meteorology 31, 194-211.

Reda, I., Andreas, A., 2008. Solar position algorithm for solar radiation applications. Tech. rep., National Renewable Energy Laboratory, Colorado, USA. 
Rigollier, C., 2004. The method heliosat-2 for deriving shortwave solar radiation from satellite images. Solar Energy 77 (2), 159-169.

Schmetz, J., Pili, P., Tjemkes, S., Just, D., Kerkmann, J., Rota, S., Ratier, A., 2002. An introduction to meteosat second generation (MSG). Bulletin of the American Meteorological Society 83 (7), 977 - 992.

Sengupta, M., Gotseff, P., Stoffel, T., 24-28 September 2012. Evaluation of photodiode and thermopile pyranometers for photovoltaic applications. In: Proceedings of the 27th European Photovoltaic Solar Energy Conference and Exhibition. Frankfurt, Germany.

Stuhlmann, R., Rieland, M., Paschke, E., 1990. An improvement of the IGMK model to derive total and diffuse solar radiation at the surface from satellite data. Journal of Applied Meteorology 29 (7), 586-603.

Wamukonya, N., 2007. Solar home system electrification as a viable technology option for Africa's development. Energy Policy 35 (1), $6-14$.

Wentzel, M., Pouris, A., 2007. The development impact of solar cookers: a review of solar cooking impact research in south africa. Energy Policy 35 (3), 1909 - 1919.

Zelenka, A., Perez, R., Seals, R., Renné, D., 1999. Effective accuracy of satellite-derived hourly irradiances. Theoretical and Applied Climatology 62 (3-4), 199-207. 